\title{
BMJ Open Diabetes mellitus and the risk of ovarian cancer: a systematic review and meta-analysis of cohort and case- control studies
}

\author{
Lihai Wang $\mathbb{D},{ }^{1}$ Lei Zhong, ${ }^{2}$ Bin Xu, ${ }^{1}$ Min Chen, ${ }^{1}$ Hongxiao Huang ${ }^{1}$
}

To cite: Wang $L$, Zhong $L$, $\mathrm{Xu} \mathrm{B}$, et al. Diabetes mellitus and the risk of ovarian cancer: a systematic review and meta-analysis of cohort and case-control studies. BMJ Open 2020;10:e040137. doi:10.1136/ bmjopen-2020-040137

- Prepublication history and supplemental material for this paper are available online. To view these files, please visit the journal online (http://dx.doi. org/10.1136/bmjopen-2020040137).

Received 06 May 2020 Revised 05 0ctober 2020 Accepted 18 November 2020

Check for updates

(c) Author(s) (or their employer(s)) 2020. Re-use permitted under CC BY-NC. No commercial re-use. See rights and permissions. Published by BMJ.

${ }^{1}$ Obstetrics and Gynecology, Huzhou Central Hospital, Affiliated Central Hospital, HuZhou University, Huzhou, Zhejiang, China

${ }^{2}$ Intensive Care Unit, Huzhou Central Hospital, Affiliated Central Hospital, HuZhou University, Huzhou, Zhejiang, China

Correspondence to Dr Hongxiao Huang; perfectog@163.com

\section{ABSTRACT}

Objective Emerging evidence from observational studies (cohort and case-control studies) suggests that a history of diabetes mellitus (DM) has been linked to increased risk of ovarian cancer $(\mathrm{OC})$, but the association between them remains inconclusive. The aim of this systematic review and meta-analysis of observational studies was to clarify this association.

Design Systematic review and meta-analysis. Methods We searched PubMed, Embase and the Cochrane library databases published from the inception through 9 April 2020 without language restriction. Observational studies that evaluated the correlation between DM and the incidence of $\mathrm{OC}$ were included in our study. Relative risk (RR) with $95 \% \mathrm{Cl}$ was pooled by use of a random-effects model.

Results A total of 36 epidemiological articles, including 9 case-control and 27 cohort studies, were finally enrolled, consisting of 14496 incident cases of OC. Synthesised RRs of developing OC by history of DM were 1.20 (95\% $\mathrm{Cl}=1.10$ to 1.31$)$ for all eligible studies, $1.08(95 \% \mathrm{Cl}=0.77$ to 1.53$)$ for case-control studies and $1.22(95 \% \mathrm{Cl}=1.11$ to 1.33) for cohort studies. The above-mentioned positive association persisted across most of subgroup analyses, whereas it was not significant among studies from North American and European countries, level of unadjusted, and patients with low-quality and gestational DM group. The cumulative meta-analysis and sensitivity analysis showed pooled effect was stable and reliable, and no apparent publication bias was identified in this study.

Conclusions Our study found weaker but still association between DM and OC risk. However, further well-designed prospective studies that control for potential confounders are warranted.

\section{INTRODUCTION}

Diabetes mellitus (DM), characterised as hyperglycaemia, is a rock-ribbed and costly chronic ailment metabolic disease, ${ }^{1}$ divided into four different subtypes-type 1 DM (T1DM), type 2 DM (T2DM), gestational DM (GDM) and other specific categories of diabetes. ${ }^{2}$ The International Diabetes
Strengths and limitations of this study

- Largest systematic review and meta-analysis examining diabetes mellitus (DM) and the risk of ovarian cancer (OC).

- We also investigated the link between type 1DM, type $2 \mathrm{DM}$ or gestational DM and OC risk, respectively, which might be more generalisable than previous published meta-analyses.

- The sensitivity analysis and cumulative metaanalysis showed pooled effect was stable and reliable, and no apparent publication bias was identified in our study.

- Substantial heterogeneity was observed among these studies.

Federation report of 2017 has estimated that the number of DM will reach approximately 693 million $(9.9 \%)$ by 2045 , up over 1.5 -fold from 451 million $(8.4 \%)$ in 2017 among adults aged 18-99 years worldwide. ${ }^{3}$ That is, the number of DM will continue to rise due to the increasing ageing population and prevalence of rising obesity, recognised as a global public health issue challenge of the 21st century across the world. ${ }^{45}$

Ovarian cancer (OC), as a leading cause of death in women with gynaecological malignancy, is the fifth leading cause of carcinomarelated death in women, with a 5 -year survival rate varying from $30 \%$ to $40 \% .{ }^{6}$ The Global Cancer Observatory predicted that in 2018 there are 295414 people with OC and the incidence of this disease worldwide increased by $47 \%$ in 2040 estimates (434 184) ${ }^{8}$ Furthermore, in the last 30 years, the cure rate for OC has barely budged. ${ }^{9}$

Too well known, the ovarian disease, which is located deep in the pelvic cavity, lacks early identifiable clinical symptoms, specific laboratory indicators as well as effective screening strategies, making early lesions difficult to detect. ${ }^{10}$ Therefore, the majority 
of patients are already diagnosed in an advanced stage owing to the insidious onset of OC. ${ }^{11}{ }^{12}$ Early identification and intervention is of vital significance in controlling cancer, especially for OC; unfortunately, few modifiable risk factors for this cancer are well documented such as smoking, hormonal replacement therapy and dietary factors. ${ }^{1314}$ Besides, other immutable risk factors included age of menarche, age of natural menopause, endometriosis and so on. ${ }^{13}$

In recent years, the causal relationship between DM and cancer risk has been widely concerned in cancer prevention research. Accumulating lines of evidence have demonstrated that DM is associated with greater risk of certain types of cancer at multiple sites, such as pancreatic, liver and endometrium cancer. ${ }^{15-20}$ Nonetheless, the relationship between DM and the observed excess risk of cancer may be a result of confounding factors such as age, obesity, physical activity and exogenous insulin therapy. ${ }^{152122}$

In recent decades, there are several epidemiological observational studies in this area since the first study investigating the association between DM and subsequent risk of OC in women was published. Several cohort ${ }^{23-26}$ and case-control ${ }^{27}$ studies have been reported that a history of DM is associated with an augmented risk of OC, however, other relevant studies found a negative significant association. ${ }^{28-31}$ Because obesity or high body mass index (BMI) has been regarded as a risk factor for both DM and OC, it remains unclear as to whether or not DM is associated with an increased OC risk on account of confounding by this factor. Studies in recent years have shown that DM may be closely related to OC, but epidemiological findings between them remain open to discussion.

In view of these conflicting results, we decided to update a meta-analysis of case-control and cohort studies to clarify whether there is an association between DM and OC risk in women.

\section{METHODS}

This meta-analysis was performed and reported based on the Meta-analysis Of Observational Studies in Epidemiology protocol checklist ${ }^{32}$ and Preferred Reporting Items for Systematic Reviews and Meta-Analyses guidelines ${ }^{33}$ (online supplemental file 1).

\section{Patient and public involvement}

Since our meta-analysis is based on previous published researches, patient and public involvement is not required.

\section{Search strategy and selection criteria}

Online databases, such as PubMed, Embase and the Cochrane library databases, were searched from the inception to 9 April 2020 for observational studies. The inclusion criteria were as follows: (1) original observational studies (cohort and casecontrol studies), (2) evaluating the association between DM and OC risk, (3) the risk estimates were reported, (4) human population, (5) without language restriction. The Medical Subject Headings keywords were as follows: "diabetes mellitus", "diabetes mellitus, type 1", "diabetes mellitus, type 2", "diabetes, gestational", "ovarian neoplasms", "ovarian cancer", "cohort studies", "case-control studies". A comprehensive search strategy was provided in online supplemental file 2. In addition, we searched the potentially eligible bibliographies of relevant articles for the purpose of completeness. The exclusion criteria in this meta-analysis were: randomised controlled trial, case reports, letters, reviews or animals studies. Eligibility assessment was performed by two authors (LW and LZ).

First, these two authors excluded duplicates via a reference manager. Second, the two authors read the title and abstract to further screen the eligible studies. Finally, we included the studies by reviewing the full text. Any disagreements were solved by means of discussion.

\section{Data extraction}

Data were extracted by one author (LW), and then checked by a second investigator (LZ). The main extracted information is described in tables 1 and 2. The association between DM and OC was the primary outcome of interest of our study.

\section{Assessment of study quality}

The Newcastle-Ottawa Scale (NOS) score was employed to evaluate the study quality of observational studies (cohort and case-control studies), with a maximum score of 9, of which 0-3, 4-6 and 7-9 scores were considered as low, fair and high quality, respectively. ${ }^{34}$

\section{Assessment of risk of bias}

All selected literature was subjected to a sensitivity analysis to explore the robustness of the pooled effects. ${ }^{35}$

\section{Statistical analysis}

The effect estimates of original studies were five measures of association, including relative risk (RR), standardised incidence ratio, incidence rate ratio, $\mathrm{HR}$ and $\mathrm{OR}$. Given that the frequency of $\mathrm{OC}$ is relatively low, the last four measures were considered to yield approximately equal estimates to that of the RR. Therefore, we reported all pooled results as RR with $95 \% \mathrm{CI}^{36}$

The statistical heterogeneity was measured by $\chi^{2}$ (threshold $\mathrm{p}=0.10$ ) and quantified by the $\mathrm{I}^{2}$ statistic. The publication bias was also appraised using the funnel plot, Begg's and Egger's test. We prefer to choose the random-effects model to analyse all data due to the conservativeness of the analysed results. ${ }^{37}$ The statistical analyses were performed with the Stata V.12.0 software (StataCorp, College Station, Texas, USA). All statistical analyses were two-sided with an $\alpha$ level of 0.05 .

Prespecified subgroup analyses were carried out to identify the sources of heterogeneity between studies in accordance with the study design (case-control vs cohort studies), DM types (T1DM vs T2DM vs GDM), duration of follow-up ( $<10$ years vs $\geq 10$ years), level of adjustment (unadjusted vs adjusted and BMI adjusted vs BMI unadjusted), study quality (NOS $\geq 7 \mathrm{vs}<7$ points) and geographical areas (North America vs Europe vs Asia vs Oceania). Subsequently, a cumulative 


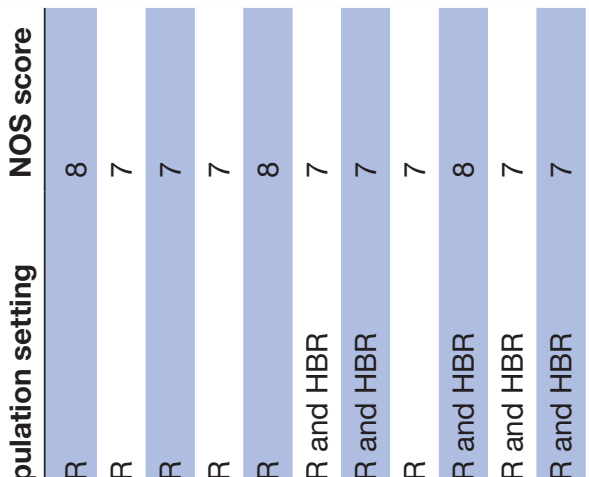

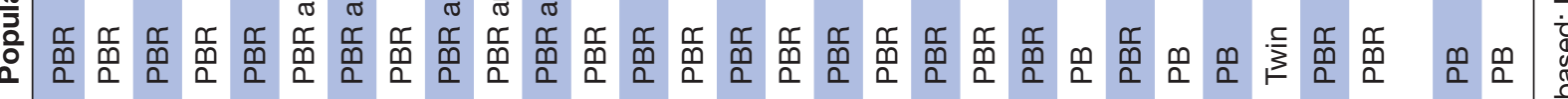

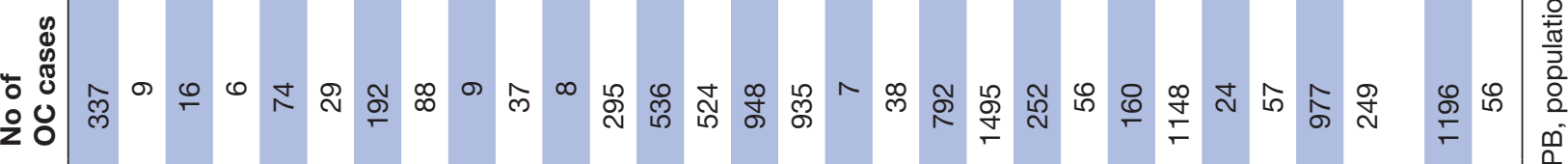

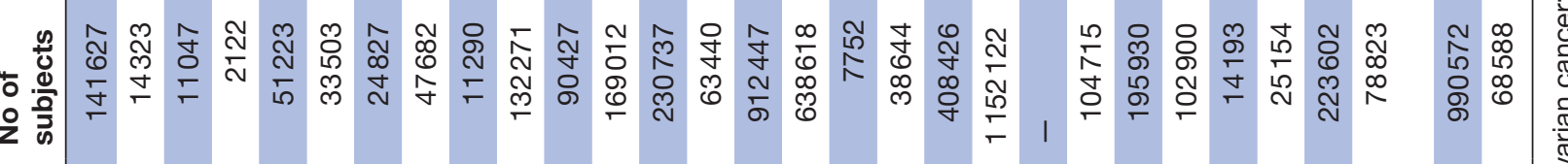

需

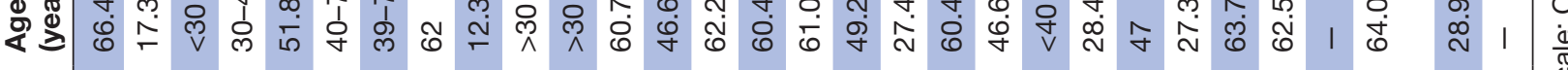

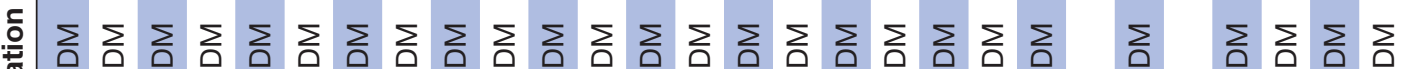

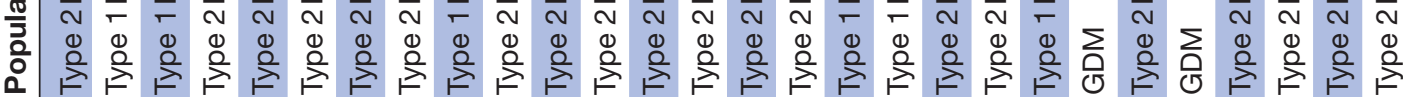

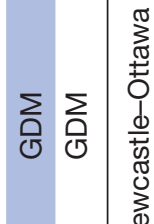

争 人

응

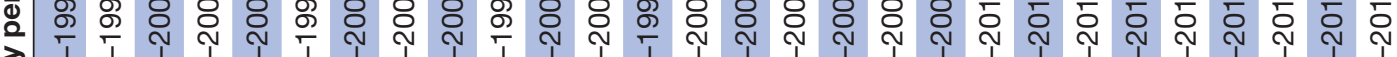

글

穴

1 1 $\frac{1}{\pi}$ 
Table 2 Baseline characteristics of the case-control studies

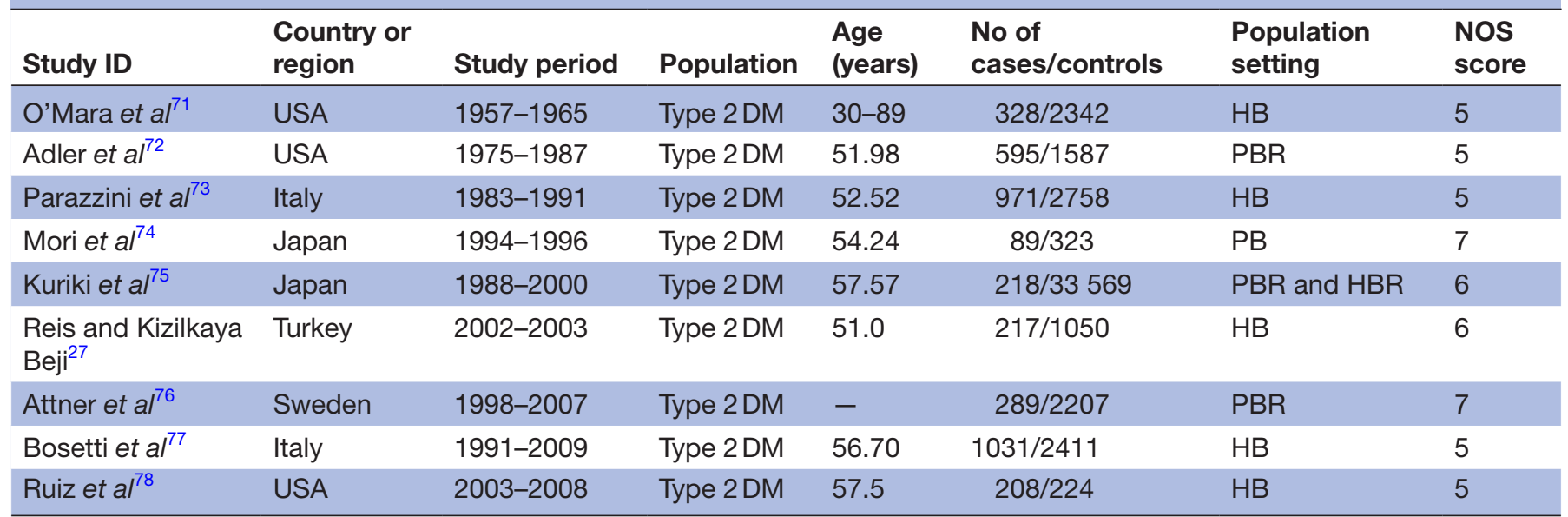

DM, diabetes mellitus; HB, hospital-based; HBR, hospital-based registry; NOS, Newcastle-Ottawa Scale; PB, population-based; PBR, population-based registry.

meta-analysis for the association between DM and the risk of OC was performed to detect the accumulated effects of DM on $\mathrm{OC}$ risk based on the publication year.

\section{RESULTS}

\section{Search results and study characteristics}

The details on the study-selection procedure are shown in figure 1. As of 9 April 2020, our search strategy initially identified 543 records and 36 citations met criteria for final inclusion after screening. These 36 publications published between 1985 and 2020, which included 9 case-control and 27 cohort studies, were eligible for final analysis, with 14496 incident cases of OC in this meta-analysis.

Among these included studies, 6 studies evaluated the relation between T1DM and risk of OC, 28 studies investigated the relationship between T2DM and OC risk, and the remaining 4 studies assessed this association between GDM and OC risk as well. With regard to geographical location, 1 study originated from Oceania, 1 in Europe and Oceania, 6 in North America, 14 in Europe and 14 studies from Asia. The follow-up period of cohort studies
Articles identified though databases

Cochrane library databases $(\mathrm{n}=165)$,

PubMed $(n=105)$, Embase $(n=273)$
Additional records identified through hand-searched $(\mathrm{n}=37)$

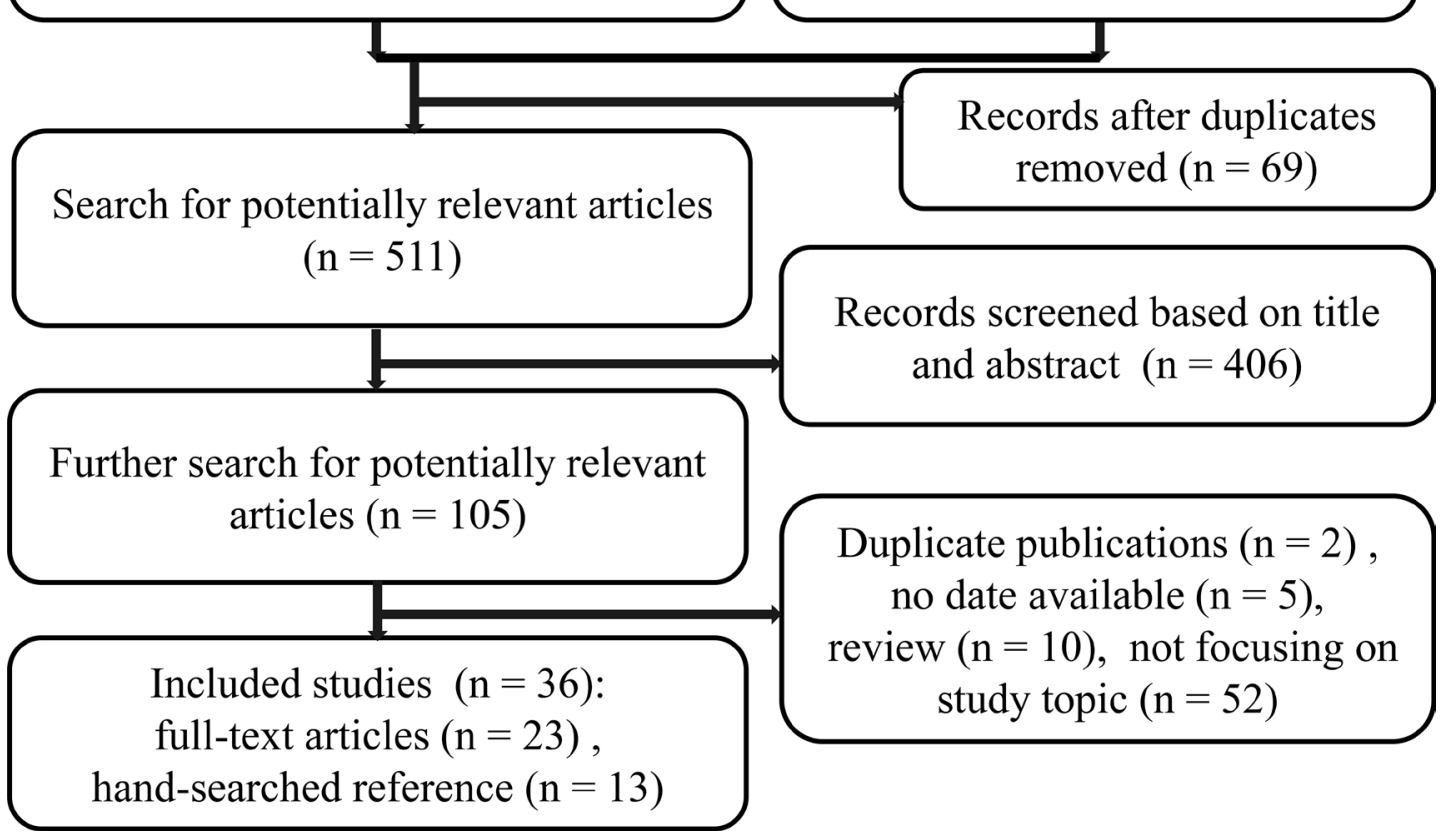

Figure 1 Article screening flow diagram. 
varied, ranging from 3.5 to 18.0 years. Studies were heterogeneous regarding age, ranging from 12.3 to 89 years. The case-control studies comprised 3946 OC cases and 46471 controls.

The main characteristics of included studies are given in tables 1 and 2.

\section{Assessment of study quality}

The NOS quality stars ranged between 5 and 9 , and the average score was 6.3 for case-control and 7.19 for cohort studies (online supplemental file 3 ). Two $(22.22 \%)$ casecontrol and $24(88.89 \%)$ cohort studies were regarded as high quality (NOS $\geq 7$ points).

The sensitivity analysis suggested no single study had significant influence on the summarised RR, which revealed the stability of pooled estimate (online supplemental file 4). No obvious evidence of publication bias was detected by inspection of the funnel plot and statistical tests (Begg's test, $\mathrm{p}=0.246$; Egger's test, $\mathrm{p}=0.132$; online supplemental file 4 ).

\section{Synthesis of primary outcome}

All 36 studies reported the association between DM and OC risk, and the combined RR was 1.20 (95\% $\mathrm{CI}=1.10$ to $1.31)$, with substantial statistical heterogeneity among these studies $\left(X^{2}=152.43, p=0.000 ; I^{2}=75.1 \%\right.$; figure 2$)$.

\section{The results of subgroup analysis}

When stratified by study design subtypes, a statistically significant effect of DM on OC risk was observed in cohort studies (RR, 1.22; $95 \% \mathrm{CI}=1.11$ to 1.33 ), however, the case-control studies found no relationship between

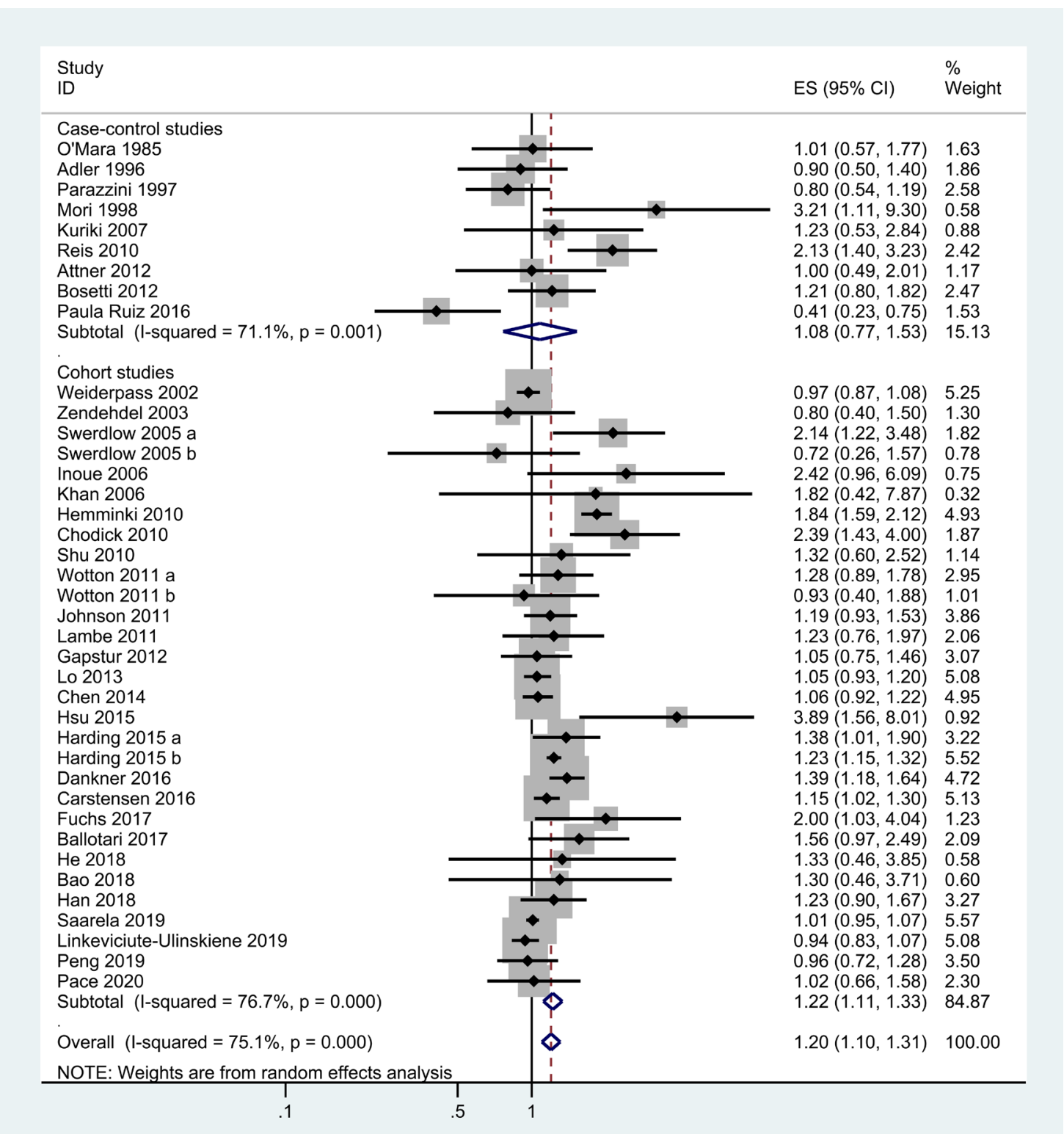

Figure 2 Meta-analysis of the association between DM and the risk of OC. DM, diabetes mellitus; ES, effect size; OC, ovarian cancer. 
$\mathrm{DM}$ and the incidence of $\mathrm{OC}$ in spite of a positive trend (RR, $1.08 ; 95 \% \mathrm{CI}=0.77$ to 1.53 ). In the analysis stratified according to DM types, a positive significant association was noted in both T1DM (RR, 1.44; $95 \% \mathrm{CI}=1.06$ to 1.95 ) and T2DM group (RR, $1.17 ; 95 \% \mathrm{CI}=1.06$ to 1.30 ), but not in GDM group (RR, $1.14 ; 95 \% \mathrm{CI}=0.90$ to 1.43 ).

A subgroup analysis was conducted considering the level of adjustment, the summary of RR in adjusted studies (RR, $1.23 ; 95 \% \mathrm{CI}=1.10$ to 1.37$)$ was more marked than in unadjusted studies (RR, $1.13 ; 95 \% \mathrm{CI}=0.98$ to 1.31$)$. Both BMI-adjusted (RR, 1.37; 95\% CI=1.16 to 1.62 ) and BMIunadjusted (RR, 1.12; 95\% CI=1.03 to 1.22 ) analyses were associated with an augmented risk of OC. In further analysis by the length of follow-up, women who experienced a long period of follow-up, that is, $\geq 10$ years (RR, 1.33; $95 \% \mathrm{CI}=1.09$ to 1.63 ) were more likely to have a higher risk of OC than those who had less than 10 years (RR, $1.14 ; 95 \% \mathrm{CI}=1.01$ to 1.29 ).

In a subgroup analysis by continent, DM was significantly positively correlated with increased OC risk among studies conducted in Asia (RR, 1.43; $95 \% \mathrm{CI}=1.20$ to 1.71 ) and Oceania (RR, 1.24; 95\% CI=1.16 to 1.32) except for European (RR, $1.15 ; 95 \% \mathrm{CI}=0.99$ to 1.35 ) and North American (RR, $0.94 ; 95 \% \mathrm{CI}=0.73$ to 1.21 ) studies. The RR was 1.24 (95\% CI=1.12 to 1.36) for high-quality studies with significant difference and $1.07(95 \% \mathrm{CI}=0.85$ to 1.35$)$ for non-high-quality studies without statistical significance (online supplemental file 4).

The results of subgroup analyses are shown in table 3 .

\section{Cumulative meta-analysis}

Although there is no association between DM and the risk of OC before Shu et al ${ }^{38}$ (cumulative RR, 1.32; 95\% $\mathrm{CI}=1.00$ to 1.74 ), subsequent studies after this study show a consistently positive association (cumulative RR, 1.32; $95 \% \mathrm{CI}=1.01$ to 1.71 ; figure 3 ).

\section{DISCUSSION}

Our systematic review and meta-analysis of 27 cohort and 9 case-control studies evaluated the association between DM and the incidence of OC, and suggested that women with DM had a $20 \%$ elevated risk of OC as compared with those without a history of DM. Similar positive finding was observed when we analysed by cohort studies, however, no meaningful difference was noted when pooled by the case-control studies. Since there is inherent nature of recall and select bias in case-control study, certain biases might lead to inaccurate reporting of causal relationship. ${ }^{39}$

A subgroup meta-analysis based on DM types indicated that the risk of OC in T1DM group (44\%) is higher than in T2DM group (17\%), while no significant association is found in GDM group. That may explain the excess risk in populations with T1DM that persons with T1DM usually require exogenous insulin treatment for the purpose of regulating blood glucose level, ${ }^{40}$ and those who are treated with insulin appear to be at higher risk to develop cancer. ${ }^{41}$ On the other hand, due to the limited numbers of eligible studies and sample
Table 3 Summary risk estimates of the subgroup analysis results of DM and OC risk

\begin{tabular}{|c|c|c|c|c|}
\hline Subgroup & Studies (n) & RR $(95 \% \mathrm{Cl})$ & $I^{2}(\%)$ & $P$ value \\
\hline Total & 36 & $1.20(1.10$ to 1.31$)$ & 75.1 & 0.000 \\
\hline \multicolumn{5}{|l|}{ Study design } \\
\hline Case-control & 9 & $1.08(0.77$ to 1.53$)$ & 71.1 & 0.001 \\
\hline Cohort & 27 & 1.22 (1.11 to 1.33$)$ & 76.7 & 0.000 \\
\hline \multicolumn{5}{|l|}{ DM types } \\
\hline Type 1 DM & 6 & 1.44 (1.06 to 1.95$)$ & 67.2 & 0.009 \\
\hline Type 2 DM & 28 & 1.17 (1.06 to 1.30$)$ & 78.5 & 0.000 \\
\hline GDM & 4 & $1.14(0.90$ to 1.43$)$ & 31.5 & 0.224 \\
\hline \multicolumn{5}{|c|}{ Geographical location } \\
\hline $\begin{array}{l}\text { North } \\
\text { America }\end{array}$ & 6 & 0.94 (0.73 to 1.21$)$ & 53.9 & 0.054 \\
\hline Europe & 14 & 1.15 (0.99 to 1.35$)$ & 81.3 & 0.000 \\
\hline Asia & 14 & $1.43(1.20$ to 1.71$)$ & 69.5 & 0.000 \\
\hline Oceania & 1 & 1.24 (1.16 to 1.32$)$ & 0.00 & 0.486 \\
\hline \multicolumn{5}{|l|}{ Follow-up } \\
\hline$<10$ years & 11 & 1.14 (1.01 to 1.29$)$ & 77.0 & 0.000 \\
\hline$\geq 10$ years & 12 & 1.33 (1.09 to 1.63 ) & 84.8 & 0.000 \\
\hline \multicolumn{5}{|c|}{ Level of adjustment } \\
\hline No & 8 & 1.13 (0.98 to 1.31$)$ & 85.0 & 0.000 \\
\hline Yes & 28 & $1.23(1.10$ to 1.37$)$ & 63.9 & 0.000 \\
\hline \multicolumn{5}{|l|}{ BMI } \\
\hline Yes & 13 & 1.37 (1.16 to 1.62$)$ & 53.5 & 0.011 \\
\hline No & 23 & $1.12(1.03$ to 1.22$)$ & 69.9 & 0.000 \\
\hline \multicolumn{5}{|l|}{ Study quality } \\
\hline NOS $<7$ & 10 & 1.07 (0.85 to 1.35$)$ & 66.7 & 0.001 \\
\hline $\mathrm{NOS} \geq 7$ & 26 & $1.24(1.12$ to 1.36$)$ & 74.2 & 0.000 \\
\hline
\end{tabular}

BMI, body mass index; DM, diabetes mellitus; GDM, gestational DM; NOS, Newcastle-Ottawa Scale; OC, ovarian cancer; RR, relative risk.

sizes, the result obtained from GDM group should be interpreted with caution. In addition, owing to an increased risk of cancer with age, the length of follow-up for patients with GDM might be too short to detect cancers in young women. ${ }^{42}$

The positive link was even more prominent arresting in studies that adjusted for covariates (ie, age, obesity, hypertension, reproductive history, smoking or alcohol) than these for unadjusted covariates analysis. Similarly, compared with subjects without BMI adjusted, the significant relationship between DM and OC also still existed and became stronger in BMI-adjustment studies. These two suggested DM is a potential independent risk factor for the development of OC.

In keeping with finding, women with DM had a less risk of OC during the early follow-up period ( $<10$ years) than during the late follow-up duration ( $\geq 10$ years). Owing that OC occurs mostly in middle-aged and elderly women, therefore, women who enjoyed a long-term follow-up are more susceptible to OC compared with those who had a short follow-up period. ${ }^{26}$ Subgroup analysis on geographical areas, the Asian and Oceania studies, yielded similar positive results as the aforementioned analyses apart from European and North American studies, which is consistent with a previous 
Study

ID

O'Mara (1985

Adler (1996)

Parazzini (1997)

Mori (1998)

Weiderpass (2002)

Zendehdel (2003)

Swerdlow a (2005)

Swerdlow b (2005)

Inoue (2006)

Khan (2006)

Kuriki (2007)

Hemminki (2010)

Chodick (2010)

Shu (2010)

Reis (2010)

Wotton a (2011)

Wotton b (2011)

Johnson (2011)

Lambe (2011)

Gapstur (2012)

Attner (2012)

Bosetti (2012)

Lo (2013)

Chen (2014)

Hsu (2015)

Harding a (2015)

Harding b (2015)

Dankner (2015)

Paula Ruiz (2016)

Carstensen (2016)

Fuchs (2017)

Ballotari (2017)

$\mathrm{He}$ (2018)

Bao (2018)

Han (2018)

Saarela (2019)

Linkeviciute-Ulinskiene (2019)

Peng (2019)

Pace (2020)
ES $(95 \% \mathrm{Cl})$

$1.01(0.57,1.78)$

$0.95(0.65,1.39)$

$0.87(0.66,1.15)$

$1.03(0.69,1.53)$

$0.97(0.79,1.20)$

$0.96(0.80,1.14)$

$1.08(0.83,1.41)$

$1.05(0.82,1.35)$

$1.11(0.86,1.44)$

$1.12(0.87,1.44)$

$1.12(0.89,1.42)$

$1.24(0.93,1.65)$

$1.32(1.00,1.74)$

$1.32(1.01,1.71)$

$1.37(1.06,1.77)$

$1.36(1.08,1.72)$

$1.34(1.06,1.68)$

$1.32(1.08,1.63)$

$1.32(1.08,1.60)$

$1.30(1.08,1.56)$

$1.28(1.07,1.54)$

$1.28(1.08,1.52)$

$1.26(1.08,1.47)$

$1.24(1.08,1.43)$

$1.27(1.10,1.47)$

$1.28(1.11,1.46)$

$1.26(1.13,1.42)$

$1.27(1.14,1.42)$

$1.24(1.11,1.39)$

$1.23(1.11,1.37)$

$1.24(1.12,1.38)$

$1.25(1.13,1.38)$

$1.25(1.13,1.38)$

$1.25(1.13,1.38)$

$1.25(1.13,1.38)$

$1.23(1.12,1.35)$

$1.21(1.11,1.33)$

$1.20(1.10,1.31)$

$1.20(1.10,1.31)$

Figure 3 Cumulative meta-analysis of the association between DM and risk of OC. DM, diabetes mellitus; ES, effect size; OC, ovarian cancer.

meta-analysis described by Zhang et al. ${ }^{43}$ Geographical variation in the incidence of OC in women worldwide might explain such heterogeneity. The significant association was consistent in high-quality studies (NOS $\geq 7$ points) except for non-high-quality studies (NOS $<7$ points).

To our knowledge, only three previous meta-analyses were published in this field. In 2013, Lee $e t a l^{4}$ performed a first meta-analysis with 7 case-control and 11 cohort studies, and supported that patients with DM have a $17 \%$ increased risk of OC compared with patients without DM. A subsequent meta-analysis carried out by Wang et al in 2017 with 14 cohort studies exposed that DM is associated with a $19 \%$ raised risk of OC, ${ }^{45}$ which was further confirmed by a meta-analysis with 15 cohort studies (32\%) later the same year. ${ }^{43}$ Our results, in accordance with these relevant studies, suggested that DM is correlated with a $20 \%$ increased risk of OC, and a significant positive association between them was observed in cohort studies $(22 \%)$ but not in case-control studies $(8 \%)$. Furthermore, the result of cumulative meta-analysis showed that it is not until in Shu et $a l^{38}$ that aforementioned positive result first appeared and the association tended to be stable thereafter.

The underlying carcinogenesis effect of DM to ovary was not completely uncovered at present, but several plausible mechanisms have been postulated to explain the links between them. Previous studies have shown that the neoplastic process has been considered to influenced by DM through these mechanisms, mainly including hyperglycaemia, hyperinsulinaemia and chronic inflammation. ${ }^{46} 47$ Because of a prolonged exposure to inflammation and hyperglycaemic condition, the reiterant lesion and repair cycles which are associated with incessant ovulation process could be slowed down, thus, resulting in an underlying risk of 
OC. ${ }^{48}$ Studies have shown that the hyperglycaemic state of patients with DM produces many of inflammatory cytokines, such as tumour necrosis factor- $\alpha$, interleukin- $1 \beta$ (IL-1 $\beta$ ) and IL-6, thereby facilitating a tumour-favourable microenvironment and potentially causing immune hyperactivation and tumour cell growth. ${ }^{49}$ Moreover, previous research confirmed that higher concentration of glucose is associated with an elevated expression level of vascular endothelial growth factor, and the latter has been known as a potent proangiogenic factor, ${ }^{51}$ indicating a tumour-promotion effect of DM. Biologically, an excess of insulin, as a growth factor, may stimulate the growth of tumour, whether endogenous or exogenous. ${ }^{52}$ Besides, several oral antihyperglycaemic therapies (sulfonylureas) have been shown to increase risk of cancer development. ${ }^{53}$ However, metformin, as an insulin sensitiser, may reduce this risk mediated by stimulation of AMP-activated protein kinase and inhibition of gluconeogenesis in the liver. ${ }^{54}$

Various strengths of our meta-analysis should be mentioned. First, this update study included a comprehensive search strategy, a great number of participants, a detailed subgroup and sensitivity analysis, which provided a more reliable estimate of the association between DM and OC risk. Second, we investigated the link between T1DM, T2DM or GDM and the risk of OC, respectively, which might be more generalisable than the previous three meta-analyses. Third, most of the included observational studies have controlled at least one potential confounder, such as age, BMI, obesity, drinking and smoking habits, as well as regular physical exercise, suggesting the reliability of the outcomes. Finally, in a cumulative meta-analysis by publication date, the $95 \%$ CIs became progressively narrower as the number of sample size increases, indicating increased estimation accuracy of risk estimates.

However, the present study has several limitations. First, the aggregated data of our study were originated from observational studies, thus, the causality between DM and the prevalence of OC remains speculative. Second, the heterogeneity among the individual studies was substantial, so does in subgroup analysis. Finally, although the majority of eligible studies adjusted for many potential confounders, we could not determine the influence of other various factors such as different treatment modalities (eg, sulfonylureas, insulinsensitising agents and insulin) of DM, oral contraceptive use and hormone replacement therapy. Therefore, further trials are warranted to clarify the association.

\section{CONCLUSIONS}

Accumulated evidence from cohort and case-control studies suggested that women with a history of DM have a higher risk of OC than those without, despite significant heterogeneity among individual studies. However, further high-quality studies with prospective design that are adequately controlled for potential confounding factors should be conducted to identify our results.
Acknowledgements The authors would like to thank all the anonymous reviewers for their invaluable comments and suggestions on improving the quality of this study.

Contributors HH, LW and LZ conceived the study idea and designed the study. LW and $L Z$ collected literature, reviewed the articles, collected the data and performed all data analyses. LW, LZ, HH, BX and MC were responsible for drafting of the manuscript. All the authors approved the final version of this manuscript.

Funding The authors have not declared a specific grant for this research from any funding agency in the public, commercial or not-for-profit sectors.

Competing interests None declared.

Patient consent for publication Not required.

Provenance and peer review Not commissioned; externally peer reviewed.

Data availability statement No data are available. All data are fully available without restriction.

Supplemental material This content has been supplied by the author(s). It has not been vetted by BMJ Publishing Group Limited (BMJ) and may not have been peer-reviewed. Any opinions or recommendations discussed are solely those of the author(s) and are not endorsed by BMJ. BMJ disclaims all liability and responsibility arising from any reliance placed on the content. Where the content includes any translated material, BMJ does not warrant the accuracy and reliability of the translations (including but not limited to local regulations, clinical guidelines, terminology, drug names and drug dosages), and is not responsible for any error and/or omissions arising from translation and adaptation or otherwise.

Open access This is an open access article distributed in accordance with the Creative Commons Attribution Non Commercial (CC BY-NC 4.0) license, which permits others to distribute, remix, adapt, build upon this work non-commercially, and license their derivative works on different terms, provided the original work is properly cited, appropriate credit is given, any changes made indicated, and the use is non-commercial. See: http://creativecommons.org/licenses/by-nc/4.0/.

ORCID iD

Lihai Wang http://orcid.org/0000-0002-0310-8143

\section{REFERENCES}

1 Padilla-Martínez F, Collin F, Kwasniewski M, et al. Systematic review of polygenic risk scores for type 1 and type 2 diabetes. Int J Mol Sci 2020;21:1703.

2 Seino Y, Nanjo K, Tajima N, et al. Report of the Committee on the classification and diagnostic criteria of diabetes mellitus. Diabetol Int 2010;1:2-20.

3 International Diabetes Federation. IDF diabetes atlas. 9th ED. Brussels, Belgium: international diabetes Federation. secondary international diabetes Federation. IDF diabetes atlas. 9th ed. Brussels, Belgium: International Diabetes Federation, 2019. https:// diabetesatlas.org/upload/resources/material/20200302_133351_ IDFATLAS9e-final-web.pdf

4 Mulyani WRW, Sanjiwani MID, Sandra, et al. Chaperone-Based therapeutic target innovation: heat shock protein 70 (Hsp70) for type 2 diabetes mellitus. Diabetes Metab Syndr Obes 2020;13:559-68.

5 Rachdaoui N. Insulin: the Friend and the foe in the development of type 2 diabetes mellitus. Int J Mol Sci 2020;21:1770.

6 Nimmagadda S, Penet M-F. Ovarian cancer targeted theranostics. Front Oncol 2019;9:1537.

7 Bergsten TM, Burdette JE, Dean M. Fallopian tube initiation of high grade serous ovarian cancer and ovarian metastasis: mechanisms and therapeutic implications. Cancer Lett 2020;476:152-60.

8 Global Cancer Observatory. Secondary global cancer Observatory, 2020. Available: http://gco.iarc.fr/tomorrow/graphic-isotype? type $=0 \&$ type_sex $=0 \&$ mode $=$ population $\&$ sex $=2 \&$ populations $=900 \&$ cancers $=25 \&$ age_group $=$ value\&apc_male $=0 \& a p c \_$female $=0 \&$ print $=0$ [Accessed April 18, 2020].

9 Arend R, Martinez A, Szul T, et al. Biomarkers in ovarian cancer: to be or not to be. Cancer 2019;125 Suppl 24:4563-72.

10 Loret N, Denys H, Tummers P, et al. The role of epithelial-tomesenchymal plasticity in ovarian cancer progression and therapy resistance. Cancers 2019;11:838.

11 Ferlay J, Soerjomataram I, Dikshit R, et al. Cancer incidence and mortality worldwide: sources, methods and major patterns in GLOBOCAN 2012. Int. J. Cancer 2015;136:E359-86.

12 Bacalbasa N, Balescu I, Vilcu M, et al. The risk of para-aortic lymph node metastases in apparent early stage ovarian cancer. Medicina 2020;56:108. 
13 Mallen AR, Townsend MK, Tworoger SS. Risk factors for ovarian carcinoma. Hematol Oncol Clin North Am 2018;32:891-902.

14 Stewart C, Ralyea C, Lockwood S. Ovarian cancer: an integrated review. Semin Oncol Nurs 2019;35:151-6.

15 Linkeviciute-Ulinskiene D, Patasius A, Zabuliene L, et al. Increased risk of site-specific cancer in people with type 2 diabetes: a national cohort study. Int J Environ Res Public Health 2019:17:246.

16 Wideroff L, Gridley G, Chow W-H, et al. Cancer incidence in a population-based cohort of patients hospitalized with diabetes mellitus in Denmark. JNCl Journal of the National Cancer Institute 1997;89:1360-5.

17 Oberaigner W, Ebenbichler C, Oberaigner K, et al. Increased cancer incidence risk in type 2 diabetes mellitus: results from a cohort study in Tyrol/Austria. BMC Public Health 2014;14:1058.

18 Wang Y, Wang B, Yan S, et al. Type 2 diabetes and gender differences in liver cancer by considering different confounding factors: a meta-analysis of cohort studies. Ann Epidemiol 2016;26:764-72.

19 Song S, Wang B, Zhang X, et al. Long-Term diabetes mellitus is associated with an increased risk of pancreatic cancer: a metaanalysis. PLoS One 2015;10:e0134321.

20 Liao C, Zhang D, Mungo C, et al. Is diabetes mellitus associated with increased incidence and disease-specific mortality in endometrial cancer? A systematic review and meta-analysis of cohort studies. Gynecol Oncol 2014;135:163-71.

21 Carstensen B, Read SH, Friis S, et al. Cancer incidence in persons with type 1 diabetes: a five-country study of 9,000 cancers in type 1 diabetic individuals. Diabetologia 2016;59:980-8.

22 Hasan S, Shaw SM, Gelling LH, et al. Exercise modes and their association with hypoglycemia episodes in adults with type 1 diabetes mellitus: a systematic review. BMJ Open Diabetes Res Care 2018;6:e000578.

23 Fuchs $\mathrm{O}$, Sheiner E, Meirovitz M, et al. The association between a history of gestational diabetes mellitus and future risk for female malignancies. Arch Gynecol Obstet 2017;295:731-6.

24 Dankner R, Boffetta P, Balicer RD, et al. Time-Dependent risk of cancer after a diabetes diagnosis in a cohort of 2.3 million adults. Am $J$ Epidemiol 2016;183:1098-106.

25 Harding JL, Shaw JE, Peeters A, et al. Cancer risk among people with type 1 and type 2 diabetes: disentangling true associations, detection bias, and reverse causation. Diabetes Care 2015;38:264-70.

26 Ballotari P, Vicentini M, Manicardi V, et al. Diabetes and risk of cancer incidence: results from a population-based cohort study in northern Italy. BMC Cancer 2017;17:703.

27 Reis N, Kizilkaya Beji N. Risk factors for ovarian cancer: results from a hospital-based case-control study. Turkiye Klinikleri Journal of Medical Sciences 2010;30:79-87.

28 Han K-T, Cho G, Kim E. Evaluation of the association between gestational diabetes mellitus at first pregnancy and cancer within 10 years postpartum using National health insurance data in South Korea. Int J Environ Res Public Health 2018;15:2646.

$29 \mathrm{He} \mathrm{X,} \mathrm{Shi} \mathrm{L,} \mathrm{Wu} \mathrm{J.} \mathrm{Retrospective} \mathrm{database} \mathrm{analysis} \mathrm{of} \mathrm{cancer} \mathrm{risk} \mathrm{in}$ patients with type 2 diabetes mellitus in China. Curr Med Res Opin 2018;34:1089-98.

30 Chen H-F, Chang Y-H, Ko M-C, et al. A large scale population-based cohort study on the risk of ovarian neoplasm in patients with type 2 diabetes mellitus. Gynecol Oncol 2014;134:576-80.

31 Gapstur SM, Patel AV, Diver WR, et al. Type II diabetes mellitus and the incidence of epithelial ovarian cancer in the cancer prevention study-II nutrition cohort. Cancer Epidemiology Biomarkers \& Prevention 2012;21:2000-5.

32 Stroup DF, Berlin JA, Morton SC. Meta-Analysis of observational studies in epidemiology: a proposal for reporting. meta-analysis of observational studies in epidemiology (moose) group. Jama 2000;283:2008-12.

33 Moher D, Liberati A, Tetzlaff J, et al. Preferred reporting items for systematic reviews and meta-analyses: the PRISMA statement. BMJ 2009;339:b2535.

34 Stang A. Critical evaluation of the Newcastle-Ottawa scale for the assessment of the quality of nonrandomized studies in metaanalyses. Eur J Epidemiol 2010;25:603-5.

35 Higgins JPT, Green S, Cochrane Collaboration. Cochrane handbook for systematic reviews of interventions. Chichester, England ; Hoboken, NJ: Wiley-Blackwell, 2008.

36 Siristatidis C, Sergentanis TN, Kanavidis P, et al. Controlled ovarian hyperstimulation for IVF: impact on ovarian, endometrial and cervical cancer-a systematic review and meta-analysis. Hum Reprod Update 2013;19:105-23.
37 Borenstein M, Hedges LV, Higgins JPT, et al. A basic introduction to fixed-effect and random-effects models for meta-analysis. Res. Synth. Method 2010;1:97-111.

38 Shu X, Ji J, Li X, et al. Cancer risk among patients hospitalized for type 1 diabetes mellitus: a population-based cohort study in Sweden. Diabet Med 2010;27:791-7.

39 Setia M. Methodology series module 2: case-control studies. Indian J Dermatol 2016;61:146-51.

40 Smith U, Gale EAM. Does diabetes therapy influence the risk of cancer? Diabetologia 2009;52:1699-708.

41 Carstensen B, Witte DR, Friis S. Cancer occurrence in Danish diabetic patients: duration and insulin effects. Diabetologia 2012;55:948-58.

42 Wang Y, Yan P, Fu T, et al. The association between gestational diabetes mellitus and cancer in women: a systematic review and meta-analysis of observational studies. Diabetes Metab 2020;46:461-71.

43 Zhang D, Li N, Xi Y, et al. Diabetes mellitus and risk of ovarian cancer. A systematic review and meta-analysis of 15 cohort studies. Diabetes Res Clin Pract 2017:130:43-52.

44 Lee J-Y, Jeon I, Kim JW, et al. Diabetes mellitus and ovarian cancer risk: a systematic review and meta-analysis of observational studies. International Journal of Gynecologic Cancer 2013;23:402-12.

45 Wang L, Wang L, Zhang J. Association between diabetes mellitus and subsequent ovarian cancer in women: a systematic review and meta-analysis of cohort studies. Medicine 2017;96:e6396.

46 Kellenberger LD, Bruin JE, Greenaway J, et al. The role of dysregulated glucose metabolism in epithelial ovarian cancer. $J$ Oncol 2010;2010:514310:10-13.

47 Weinert LS. International association of diabetes and pregnancy study groups recommendations on the diagnosis and classification of hyperglycemia in pregnancy: Comment to the International association of diabetes and pregnancy study groups consensus panel. Diabetes Care 2010;33:e97.

48 Piek JMJ, Kenemans P, Verheijen RHM. Intraperitoneal serous adenocarcinoma: a critical appraisal of three hypotheses on its cause. Am J Obstet Gynecol 2004;191:718-32.

49 Gupta S, Gambhir JK, Kalra OP, et al. Association of biomarkers of inflammation and oxidative stress with the risk of chronic kidney disease in type 2 diabetes mellitus in North Indian population. $J$ Diabetes Complications 2013;27:548-52.

50 Chang S-C, Yang W-CV. Hyperglycemia, tumorigenesis, and chronic inflammation. Crit Rev Oncol Hematol 2016;108:146-53.

51 Giannarelli R, Aragona M, Coppelli A, et al. Reducing insulin resistance with metformin: the evidence today. Diabetes Metab 2003;29:6S28-6S35.

52 Suh S, Kim K-W, Diabetes KKW. Diabetes and cancer: cancer should be screened in routine diabetes assessment. Diabetes Metab $J$ 2019:43:733-43.

53 Hussain S, Chowdhury TA. The impact of comorbidities on the pharmacological management of type 2 diabetes mellitus. Drugs 2019;79:231-42.

54 Faramarzi L, Dadashpour M, Sadeghzadeh H, et al. Enhanced antiproliferative and pro-apoptotic effects of metformin encapsulated PLGA-PEG nanoparticles on SKOV3 human ovarian carcinoma cells. Artif Cells Nanomed Biotechnol 2019;47:737-46.

55 Weiderpass $\mathrm{E}, \mathrm{Ye} \mathrm{W}$, Vainio $\mathrm{H}$, et al. Diabetes mellitus and ovarian cancer (Sweden). Cancer Causes and Control 2002;13:759-64.

56 Zendehdel K, Nyrén O, Ostenson C-G, et al. Cancer incidence in patients with type 1 diabetes mellitus: a population-based cohort study in Sweden. J Nat/ Cancer Inst 2003;95:1797-800.

57 Swerdlow AJ, Laing SP, Qiao Z, et al. Cancer incidence and mortality in patients with insulin-treated diabetes: a UK cohort study. $\mathrm{Br} \mathrm{J}$ Cancer 2005;92:2070-5.

58 Inoue M, Iwasaki M, Otani T. Diabetes mellitus and the risk of cancer: results from a large-scale population-based cohort study in Japan. Arch Intern Med 2006;166:1871-7.

59 Khan M, Mori M, Fujino Y. Site-Specific cancer risk due to diabetes mellitus history: evidence from the Japan collaborative cohort (JACC) study. Asian Pac J Cancer Prev 2006;7:253-9.

60 Hemminki K, Li X, Sundquist J, et al. Risk of cancer following hospitalization for type 2 diabetes. Oncologist 2010;15:548-55.

61 Chodick G. Heymann AD, Rosenmann L, et al. Diabetes and risk of incident cancer: a large population-based cohort study in Israel. Cancer Causes Control 2010;21:879-87.

62 Wotton CJ, Yeates DGR, Goldacre MJ. Cancer in patients admitted to hospital with diabetes mellitus aged 30 years and over: record linkage studies. Diabetologia 2011:54:527-34.

63 Johnson JA, Bowker SL, Richardson K, et al. Time-Varying incidence of cancer after the onset of type 2 diabetes: evidence of potential detection bias. Diabetologia 2011;54:2263-71. 
64 Lambe M, Wigertz A, Garmo H, et al. Impaired glucose metabolism and diabetes and the risk of breast, endometrial, and ovarian cancer. Cancer Causes Control 2011;22:1163-71.

65 SF L, Chang SN, Muo CH. Modest increase in risk of specific types of cancer types in type 2 diabetes mellitus patients. Int $J$ Cancer 2013;132:182-8.

66 Hsu P-C, Lin W-H, Kuo T-H, et al. A population-based cohort study of all-cause and site-specific cancer incidence among patients with type 1 diabetes mellitus in Taiwan. Journal of Epidemiology 2015;25:567-73.

67 Bao C, Pedersen NL, Yang R, et al. Diabetes in midlife and risk of cancer in late life: a nationwide Swedish twin study. Int $J$ Cancer 2018;143:793-800.

68 Saarela K, Tuomilehto J, Sund R, et al. Cancer incidence among Finnish people with type 2 diabetes during 1989-2014. Eur J Epidemiol 2019:34:259-65.

69 Peng Y-S, Lin J-R, Cheng B-H, et al. Incidence and relative risk for developing cancers in women with gestational diabetes mellitus: a nationwide cohort study in Taiwan. BMJ Open 2019;9:e024583.

70 Pace R, Rahme E, Dasgupta K. Gestational diabetes mellitus and risk of incident primary cancer: a population-based retrospective cohort study. J Diabetes 2020;12:87-90.

71 O'Mara BA, Byers T, Schoenfeld E. Diabetes mellitus and cancer risk: a multisite case-control study. J Chronic Dis 1985;38:435-41.
72 Adler Al, Weiss NS, Kamb ML, et al. Is diabetes mellitus a risk factor for ovarian cancer? A case-control study in Utah and Washington (United States). Cancer Causes Control 1996;7:475-8.

73 Parazzini F, Moroni S, La Vecchia C, et al. Ovarian cancer risk and history of selected medical conditions linked with female hormones. Eur J Cancer 1997;33:1634-7.

74 Mori M, Nishida T, Sugiyama T, et al. Anthropometric and other risk factors for ovarian cancer in a case-control study. Jpn J Cancer Res 1998;89:246-53.

75 Kuriki K, Hirose K, Tajima K. Diabetes and cancer risk for all and specific sites among Japanese men and women. European Journal of Cancer Prevention 2007;16:83-9.

76 Attner B, Landin-Olsson M, Lithman T, et al. Cancer among patients with diabetes, obesity and abnormal blood lipids: a population-based register study in Sweden. Cancer Causes Control 2012;23:769-77.

77 Bosetti C, Rosato V, Polesel J, et al. Diabetes mellitus and cancer risk in a network of case-control studies. Nutr Cancer 2012;64:643-51.

78 Ruiz MP, Morales-Ramirez PB, Dziadek OL, et al. Epithelial ovarian cancer and type of peritoneal insult: a case-control study. Eur $J$ Obstet Gynecol Reprod Biol 2016;205:170-3. 